\title{
The effects of social support on maternal anxiety and depression after stillbirth
}

\author{
Joanne Cacciatore PhD MSW FT ${ }^{1}$, Stephen Schnebly $\mathrm{PhD}^{1}$ and J. Frederik Froen $\mathrm{PhD}^{2}$ \\ ${ }^{1}$ College of Human Services, Arizona State University, Glendale, AZ, USA, ${ }^{2}$ Obstetrics and Gynecology, University of Oslo, \\ Oslo, Norway
}

\author{
Correspondence \\ Dr Joanne Cacciatore \\ College of Human Services, \\ Arizona State University \\ 4701 W. Thunderbird Rd. \\ Glendale \\ AZ 85306 \\ USA \\ E-mail: joanne.cacciatore@asu.edu
}

\begin{abstract}
While most births result in a live baby, stillbirth (the birth of a dead baby) occurs in nearly 1 in 110 pregnancies. This study examined whether levels of maternal anxiety and depression are lower amongst mothers who received social support after stillbirth. Using non-probability sampling, data were collected from 769 mothers residing within the USA who experienced a stillbirth within the past 18 months and for whom we have complete data. The study Maternal Observations and Memories of Stillbirth and the website http://www.momstudy.com containing the questionnaire were open in the period 8 February 2004-15 September 2005. Congruent with the family stress and coping theory, mothers of stillborn babies who perceived family support in the period after stillbirth experienced levels of anxiety and depression that were notably lower than those of their counterparts. Nurses, physicians and support groups also were important sources of support after a stillbirth; however, these sources of support alone were not statistically significant in reducing anxiety and depression in grieving mothers. Community interventions should focus on the grieving mother and her family system, including her partner and surviving children.
\end{abstract}

Keywords: community interventions, death and dying, family support, family systems, fetal death, maternal anxiety and depression, stillbirth

\section{Accepted for publication 27 July 2008}

\section{Introduction}

\section{Childbirth gone awry: stillbirth}

While a vast majority of pregnancies lead to the birth of a healthy child, the birth of a dead baby, or stillbirth, is more common than might be expected. In fact, approximately 1 in 110 pregnancies results in a stillborn child; that is, the naturally occurring, intrauterine death of a baby after the 20th completed gestational week all the way until birth (DeFrain et al. 1990, Bright 1991, Silver 2007). Worldwide, there are about 4 million sudden intrauterine infant deaths every year. Historically, minority groups have been over-represented in both fetal and infant mortality rates, and rates in developing countries are difficult to accurately calculate due to poor documentation (Copper et al. 1994, Conde-Agudelo et al. 2000, Froen 2002, Ananth et al. 2005). As a point of comparison, the annual frequency of stillbirth is more than 10 times that of sudden infant death syndrome (Fletcher 2002, Goldenberg et al. 2004, Ananth et al. 2005).

In addition to the surprising frequency of stillbirth, mothers and families often experience a variety of physical, mental and social maladies in the period after a child is born still. These deleterious effects, which include suicidal ideation, increased maternal mortality, somatisation, family disorganisation, economic deprivation, social isolation, depression, anxiety, pining and mental illness (DeFrain et al. 1990, Ney et al. 1994, Shalev 2000, Laakso \& Paunonen-Ilmonen 2002, Gundel et al. 2003, Jiong et al. 2003, Michon et al. 2003, Rubin et al. 2003, O'Connor 2005, Cacciatore 2007), make stillbirth a major public health problem facing pregnant women and their families (Bright 1991, DeFrain et al. 1990, Silver 2007).

When a baby is stillborn, the social support system of many bereaved mothers falters. Stillbirth is often an isolating, marginalising experience for women (Kirkley- 
Best \& Kellner 1982, Kavanaugh 1997, Malacrida 1999, Hankins \& Spong 2001, Laakso \& Paunonen-Ilmonen 2002, Michon et al. 2003, Goldenberg et al. 2004, Cacciatore 2007) and there exists a social discrepancy in the legitimising of grief after the death of a stillborn child versus the death of a live-born child (Dunkel-Schetter \& Bennett 1990, Mulkay 1993, Malacrida 1999). This may intensify and complicate grief (DeFrain et al. 1990, Malacrida 1999, Cacciatore 2007) or even protract grief for some, causing withdrawal from social interaction (Rando 1993). Bereaved mothers may find themselves 'at odds with the social milieu and ... forced to rely solely on her own resources to negotiate grief resolution' (Malacrida 1999, p. 507).

Rando (1984) asserts that societal support offered to a griever is commensurate with the value and worth of both the mourner and the deceased by others. This is particularly complex in the case of stillbirth, wherein the life and death are tacitly, and in some cases explicitly, unrecognised by society. Malacrida (1999) found that parents' 'expectations of support, based on their own valuation of the loss stood in contrast to the actual support they received from ... immediate and extended families, the medical community, and helping professionals' after a perinatal death (p. 510). It is this incongruence between the grieving mothers' affect and the social responses she receives that result in pathological grief. The 'social nonrecognition and nonsupport.... are precisely the types of interactions that eventually will lead parents to require therapy' (Malacrida 1999, p. 513).

Parents who experienced stillbirth reported high levels of anxiety, and this state could be reliably predicted by psychosocial conditions, including a perceived lack of support from others (Dyregrov \& Matthiesen 1987). Additionally, the probability for adverse psychological and physiological sequelae following stillbirth increases due to the complex physiological effects of both pregnancy and childbirth, a process and an event that leaves women particularly vulnerable to depression, suicidal ideation, mood disorders, dramatic biochemical changes (Affonso \& Arizmendi 1986, O'Hara 1995, Hendrick et al. 1998), and post-traumatic stress disorder (Beech \& Robinson 1985, Ballard et al. 1995, Soet et al. 2003, Slade 2006, Silver 2007). While 'loss of any type is difficult ... stillbirth is devastating' (Bright 1991, p. 3).

\section{Loss and social support}

During a crisis, there are many opportunities for supportive outreach from others (Vaux 1988). Yet, researchers historically have experienced great difficulties precisely defining social support (Vaux 1988, Hupcey 1998, Cohen et al. 2000). Despite these difficulties, social support generally is recognised as any action or relationship that has some positive benefit for a person (Hupcey
1997). There is some evidence to suggest that several factors influence social support provision, including an appraisal of need by the potential provider of support and the ability to provide that necessary support (Jung 1998). Yet, one of the most important variables in social support is the perception of its existence by the recipient. Lieberman (1986) suggests that during time of need, individuals may themselves be unable define what was supportive for them; simply, they just knew whether they felt supported or not. Personality traits also seem to have a relationship with the perception of support. Thus, even if a support provider offers a reasonably adequate level of support to a recipient, her perception of that support, according to Sarason et al. (1990), may be related to her characterological history.

Social support can be examined from the perspective of the family stress and coping theory. Significant demands that require higher levels of coping for a member of a family, namely the mother, may include chronic stressors resulting from day-to-day life as well as a precipitating traumatic event (Patterson 1988, Boss 2001). What protects her and her family, however, extends beyond the intimate family circle and includes peripheral family and friends as well as community members. Particularly in situations of significant risk, such as exposure to a traumatic life event (Masten \& Coatsworth 1998), psychological outcomes can hinge on support from others. Stress researchers focus their attention on the responses of the ecosystem and how such responses can foster or impede resiliency during a crisis (Boss 2001). Thus, social support can come from various systems within a woman's frame of reference.

Social support plays a vital role in buffering the effects of trauma and mediating stress (Lehman et al. 1986). Bereaved individuals 'who perceived the social support system available to them as high reported less depressive and somatic symptomatology' than those who reported low support (Stroebe et al. 1996, p. 1247). In the aftermath of a traumatic event, 'efforts to reduce the stressfulness ... (e.g. by providing ... information, orientation, warmth, and hope) have an essential role' in lessening severe bio-psychological distress such as neuronal changes, depression, post-traumatic stress disorder and other pathogenic factors (Shalev 2000, p. 283). The lack of social support, including that stemming from marital dissatisfaction, intensifies grief responses (LaRoche et al. 1984).

In a study of 82 mothers and 47 fathers experiencing perinatal death, Zeanah \& Harmon (1995) found that the quality of a marital relationship and social support were more important predictors of adaptation than demographics such as age, education or socio-economic status. While relationship stress may intensify after the death of a baby, the divorce rate does not increase. 
Mekosh-Rosenbaum \& Lasker (1995) found that 5.77\% of marriages ended in divorce after the death of a baby (loss group) versus $3.67 \%$ after a live-birth (control group). Mental distress and low social support, including a lack of support by family and friends, were negatively associated with marital satisfaction in both the loss and the control group, and 'those who perceive that they were well supported reported having a more positive relationship with their partners' (p. 140).

Laakso \& Paunonen-Ilmonen (2002) discovered that support groups were more important to women than to their partners. In their qualitative study of 91 women experiencing the death of a child younger than seven, women reported sensing 'permission to talk about the child's death with a fellow sufferer.... [they] wanted to get to know other mothers in a similar situation' (p. 181). In this same study, women reported that, despite marital disharmony and increased stress after a child's death, support from a partner was 'the most important form of support' (p. 182). Another study showed that women experiencing stillbirth who attended support groups for parental bereavement had significantly lower rates of post-traumatic stress symptoms, even when controlling for time (Cacciatore 2007). Mothers may experience the absence of anticipated support from their preloss circle of friends. 'Facing a grieving mother and talking about the death was insuperably difficult' for many (Laakso \& Paunonen-Ilmonen 2002, p. 182), thus, resulting in the deterioration of many important relationships for women. This may be one reason why bereaved mothers seek out like others: 'Such individuals may be less threatened and upset by signs of distress.... and therefore be less likely to close off discussions of feelings to push the person to a quick recovery' (Lehman et al. 1986, p. 439; Pennebaker 1990).

\section{Expectations}

Social support is a consistent feature in research highlighting helpful interventions for mothers and their families in crisis (DeFrain et al. 1990, Pauw 1991, Lasker \& Toedter 1994, Sheldon 1998, Malacrida 1999, Stroebe et al. 1999, Cacciatore 2007, Silver 2007). For the purposes of this paper, we focus on the potentially beneficial aspects of social support for mothers of stillborn babies. While other studies have examined bereavement and various types of social support (Mekosh-Rosenbaum \& Lasker 1995, Vanderwerker \& Prigerson 2003, Gold 2007), with some even focusing on mothers' experiences after the death of a child (Laakso \& Paunonen-Ilmonen 2002), no studies have focused their attention on how various types of perceived social support are associated with levels of anxiety and depression specifically amongst mothers of stillborn infants.
Based on a review of the extant literature on stillbirth and social support, we have derived two general hypotheses regarding the relationships between social support and maternal levels of anxiety and depression. First, we expect that the forms of social support considered in the study (doctor, nurse, family and support group) will be negatively related to levels of anxiety and depression amongst stillbirth mothers. Based on previous research, we expect that the strongest negative associations will be observed between group support and levels of maternal anxiety and depression.

Second, while each form of social support is expected to be negatively related to anxiety and depression, we also hypothesise that multiple layers of social support will interact to influence maternal anxiety and depression beyond their additive effects. For example, women who received support from both their families and their caregivers are expected to have anxiety and depression scores that are lower than mothers who received support from only one of these two sources. Given the limitations in defining social support, we are using the mother's perception of support as the assessment criterion, recognising that any specific definitions imposed by the research team would not accurately express the mother's experiences (Antonucci \& Israel 1986, Lieberman 1986). Quite simply, what may be supportive to one mother may be wholly unsupportive to another. What is in question is not the type of support but rather whether or not she experienced support from others; and, if so, from whom support was received. Then, ultimately, its effects, if any, on her anxiety and depression. More specifically, we examine whether levels of maternal anxiety and depression are lower amongst mothers who received social support from each of four unique sources: (i) doctor support during stillbirth, (ii) nurse support during stillbirth, (iii) family support in the period after stillbirth and (iv) support group participation during the period after stillbirth.

Taking these hypothesised interactions to their ultimate conclusion, we expect to find that women who received the full complement of support that should be available to them (i.e. support from each of the four sources considered in the study) will be those with the lowest levels of post-stillbirth anxiety and depression.

\section{Methods}

We searched 12 Internet search engines and directories for the terms 'stillbirth', 'pregnancy loss', 'fetal loss' or 'fetal death'. Where possible, we included all inflections of the terms, and only in pages in English updated in the last 3 months. From the first 100 matches from each search engine, 749 webpages were identified. These were examined to identify organisations and websites 
offering free information on pregnancy and childbirth (including stillbirth), or information, support or web forums for families affected by stillbirth. We excluded sites presenting only sporadic information, such as online scientific journals, dictionaries or databases, and sites for scientific, professional or governmental use, such as the American College of Obstetrics and Gynecology or the National Center for Health Statistics. The 104 sites or organisations were invited to recruit women affected by stillbirth to respond to a questionnaire through their websites, mailing lists, newsletters, forums or other means using ready-made invitations. Thirty-seven organisations accepted.

\section{Measures}

The dependent variables of the study were constructed from the 25-item Hopkins Symptom Checklist (HSCL) found in the Maternal Observations and Memories of Stillbirth (MOMS) study survey. In use for over 50 years, the HSCL has provided indicators of mental distress for a multitude of uses, including medical trials, treatment evaluations, and family practice and family planning services (Parloff et al. 1954, Hesbacher et al. 1980, Olsen et al. 2006). Previous studies have demonstrated the validity and reliability of the HSCL instrument across numerous cultural contexts and subgroups, including pregnant women (Kaaya et al. 2002).

The HSCL includes 10 anxiety survey items and 15 depression items. Responses are coded 1-4 $(1=$ 'Not at all'; 2 = 'A little'; 3 = 'Quite a bit'; 4 = 'Extremely'), with higher scores indicating increased levels of mental distress. The study's two dependent variables, labelled Anxiety and Depression, reflect a respondent's mean scores on the HSCL's 10 anxiety and 15 depression items.

The study's four explanatory measures identify the perceived presence (or absence) of various forms of social support during and after the stillbirth experience. Doctor Support and Nurse Support are binary measures coded 1 if the respondent reported having received 'support' or 'great support' from doctors or nurses during the stillbirth experience, and coded 0 if the respondent perceived no such support. Family Support and Group Support are similarly coded binary measures that identify whether family members or a support group provided a mother with social support in the period after stillbirth.

In addition to these explanatory variables, the study incorporates numerous control measures that account for respondent characteristics that also may be associated with levels of maternal anxiety and depression. Chronic Health Problems During Pregnancy and Abuse During Pregnancy are binary variables (coded $1=$ yes, $0=$ no) that identify respondents who suffered from chronic health problems during the pregnancy that resulted in stillbirth and those who were victims of physical or psychological abuse during the pregnancy. Another binary variable, labelled Intrapartum Death, differentiates mothers whose stillborn baby died during birth (coded 1) from those whose baby died prior to the onset of labour (coded 0 ). Three continuous control measures identify the number of years since the stillbirth occurred (Years Since Stillbirth), the number of pregnancies prior to the stillbirth (Number of Previous Pregnancies), and the respondent's age at the time of the stillbirth (Maternal Age at Stillbirth). Additional demographic control measures (each coded $1=$ yes, $0=$ no) identify the respondent's race (Non-White Respondent), educational level (H.S. Educated), and marital status (Single, Divorced, or Widowed). Lastly, the study includes a binary measure that identifies how survey respondents were recruited into the MOMS study. Labelled Recruited into Sample, this variable differentiates respondents who actively sought participation in the study (coded 0), from those who were either recruited into the sample by others (e.g. snowball sampling) or came across MOMS study survey by accident (coded 1$)$.

\section{Analytic strategy}

Our analysis utilises SPSS 14 statistical software and begins with a series of eight independent samples $t$-tests that examine whether levels of anxiety and depression are lower amongst stillbirth mothers who received social support from each of the four sources considered in the study. We next estimate two multiple ordinary least-squares (OLS) regression models to determine whether any bivariate associations between social support and anxiety/depression hold once we account for individual-level characteristics that are likely to be associated with both maternal anxiety and depression. Lastly, we estimate a series of OLS models that incorporate various two-, three- and four-way interaction terms to explore whether multiple layers of support influence depression and anxiety beyond their additive effects. Due to the non-probability sampling used in this study, however, confidence intervals and $P$-values should be interpreted with caution.

\section{Results}

The study's data were obtained from the MOMS study. Using non-probability sampling, data were collected via an online survey from February 2004 to September 2005. During this period, 2900 stillbirth mothers completed the survey. However, the sample used in the present study was restricted to 769 mothers in the USA who answered the questionnaire in its entirety and who experienced a stillbirth within the past 18 months. 
Table 1 Characteristics of eligible respondents $(N=769)$

\begin{tabular}{|c|c|c|c|c|}
\hline & Mean & SD & Minimum & Maximum \\
\hline \multicolumn{5}{|l|}{ Dependent variables } \\
\hline Anxiety scale & 1.81 & 0.50 & 1.00 & 3.70 \\
\hline Depression scale & 2.14 & 0.58 & 1.00 & 3.93 \\
\hline \multicolumn{5}{|l|}{ Independent variables } \\
\hline Years since stillbirth & 0.45 & 0.42 & 0.08 & 1.50 \\
\hline $\begin{array}{l}\text { Number of previous } \\
\text { pregnancies }\end{array}$ & 1.33 & 1.57 & 0.00 & 9.00 \\
\hline \multirow[t]{2}{*}{ Maternal age at stillbirth } & 29.15 & 5.31 & 16.00 & 45.00 \\
\hline & & & Frequency & Percentage \\
\hline \multirow{2}{*}{\multicolumn{2}{|c|}{ Doctor support during stillbirth }} & Yes & 522 & 67.9 \\
\hline & & No & 247 & 32.1 \\
\hline \multirow{2}{*}{\multicolumn{2}{|c|}{ Nurse support during stillbirth }} & Yes & 692 & 90.0 \\
\hline & & No & 77 & 10.0 \\
\hline \multirow{2}{*}{\multicolumn{2}{|c|}{ Family support after stillbirth }} & Yes & 705 & 91.7 \\
\hline & & No & 64 & 8.3 \\
\hline \multirow{2}{*}{\multicolumn{2}{|c|}{ Group support after stillbirth }} & Yes & 411 & 53.4 \\
\hline & & No & 358 & 46.6 \\
\hline \multirow{2}{*}{\multicolumn{2}{|c|}{ Chronic health problems during pregnancy }} & Yes & 272 & 35.4 \\
\hline & & No & 497 & 64.6 \\
\hline \multirow{2}{*}{\multicolumn{2}{|c|}{ Intrapartum death }} & Yes & 80 & 10.4 \\
\hline & & No & 689 & 89.6 \\
\hline \multirow{2}{*}{\multicolumn{2}{|c|}{ Abuse during pregnancy }} & Yes & 47 & 6.1 \\
\hline & & No & 722 & 93.9 \\
\hline \multirow{2}{*}{\multicolumn{2}{|c|}{ Non-white respondent }} & Yes & 88 & 11.4 \\
\hline & & No & 681 & 88.6 \\
\hline \multicolumn{2}{|l|}{ High school educated* } & Yes & 151 & 80.4 \\
\hline & & No & 618 & 19.6 \\
\hline \multicolumn{2}{|l|}{ Single, divorced or widowed $\dagger$} & Yes & 50 & 6.5 \\
\hline & & No & 719 & 93.5 \\
\hline \multirow{2}{*}{\multicolumn{2}{|c|}{ Recruited into sampleł }} & Yes & 215 & 28.0 \\
\hline & & No & 554 & 72.0 \\
\hline
\end{tabular}

* Reference is college educated. † Reference is married/cohabitating. $\ddagger$ Reference is actively sought out recruitment.
Descriptive statistics for the study's dependent and independent variables are reported in Table 1 . In regard to the extent that the mothers in our sample experienced symptoms of anxiety and depression, these results reveal an average anxiety score of 1.81 and an average depression score of 2.14 (both measured on a 4-point scale described above). This evidence that depression and anxiety are relatively common amongst mothers of stillborn infants provides further impetus to explore the correlates and causes of these forms of mental distress amongst our sample.

Table 1 reveals that family support was most common, with $91.7 \%$ of respondents reporting that they had received either 'great support' or 'support' from their family members in the period after stillbirth. The next most common sources of support were provided by nurses (90\%), doctors (67.9\%) and support groups (53.4\%). There are other important characteristics: for example, more than one-third of the sample experienced chronic health problems during the pregnancy that resulted in stillbirth, while approximately $6 \%$ of the women in the study were subjected to physical or psychological abuse during their pregnancy.

Table 2 reports the results of independent samples $t$-tests exploring whether anxiety and depression are lower amongst stillbirth mothers who received social support from doctors, nurses, families and support groups. These findings reveal that support from physicians, nurses and family members is associated with notably lower levels of both anxiety and depression. It appears that the most important and impacting form of social support is that provided by family members. More specifically, mothers of stillborn babies who perceived high family support in the period after stillbirth had mean anxiety and depression scores that were 0.19 and 0.23 units below those of their counterparts. Table 2 also reveals that while women who received support from support groups typically scored lower on the anxiety scale than those who did not, this difference in mean levels of anxiety fails to reach statistical significance. 
Table 2 Independent samples $t$-tests assessing the relationships between forms of social support and levels of maternal depression and anxiety $(N=769)$

\begin{tabular}{|c|c|c|c|c|c|c|}
\hline & \multicolumn{2}{|l|}{ Means } & \multirow{2}{*}{$\begin{array}{l}\text { Mean } \\
\text { difference }\end{array}$} & \multirow[b]{2}{*}{$t$} & \multirow{2}{*}{\multicolumn{2}{|c|}{$\begin{array}{l}95 \% \mathrm{Cl} \text { for the } \\
\text { mean difference }\end{array}$}} \\
\hline & Doctor support $(N=522)$ & No doctor support $(N=247)$ & & & & \\
\hline \multicolumn{7}{|c|}{ Dependent variable } \\
\hline Anxiety & 1.77 & 1.88 & -0.11 & $-2.95^{\star \star}$ & -0.19 & -0.04 \\
\hline Depression & $\begin{array}{l}2.10 \\
\text { Nurse support }(N=692)\end{array}$ & $\begin{array}{l}2.21 \\
\text { No nurse support }(N=77)\end{array}$ & -0.11 & $-2.49^{\star}$ & -0.20 & -0.02 \\
\hline \multicolumn{7}{|c|}{ Dependent variable } \\
\hline Anxiety & 1.79 & 1.94 & -0.14 & $-2.41^{*}$ & -0.26 & -0.03 \\
\hline Depression & $\begin{array}{l}2.12 \\
\text { Family support }(N=705)\end{array}$ & $\begin{array}{l}2.30 \\
\text { No family support }(N=64)\end{array}$ & -0.19 & $-2.73^{\star *}$ & -0.32 & -0.05 \\
\hline \multicolumn{7}{|c|}{ Dependent variable } \\
\hline Anxiety & 1.79 & 1.98 & -0.19 & $-2.93^{\star \star}$ & -0.32 & -0.06 \\
\hline Depression & $\begin{array}{l}2.12 \\
\text { Group support }(N=411)\end{array}$ & $\begin{array}{l}2.35 \\
\text { No group support }(N=358)\end{array}$ & -0.23 & $-3.13^{\star \star}$ & -0.38 & -0.09 \\
\hline \multicolumn{7}{|c|}{ Dependent variable } \\
\hline Anxiety & 1.78 & 1.84 & -0.06 & -1.67 & -0.13 & 0.01 \\
\hline Depression & 2.09 & 2.18 & -0.09 & $-2.12^{*}$ & -0.17 & -0.01 \\
\hline
\end{tabular}

${ }^{\star} P \leq 0.05$ (two-tailed). ${ }^{* *} P \leq 0.01$ (two-tailed).

\begin{tabular}{|c|c|c|c|c|}
\hline \multirow[b]{2}{*}{ Independent variables } & \multicolumn{2}{|c|}{ Model 1: Anxiety } & \multicolumn{2}{|c|}{ Model 2: Depression } \\
\hline & B & SE & B & SE \\
\hline Doctor support during stillbirth & -0.07 & 0.04 & -0.06 & 0.05 \\
\hline Nurse support during stillbirth & -0.08 & 0.06 & -0.14 & 0.07 \\
\hline Family support after stillbirth & $-0.13^{*}$ & 0.07 & $-0.21^{\star \star}$ & 0.08 \\
\hline Group support after stillbirth & -0.01 & 0.04 & -0.02 & 0.04 \\
\hline Years since stillbirth (logged) & -0.03 & 0.02 & $-0.12^{\star \star \star}$ & 0.02 \\
\hline Number of previous pregnancies (logged) & $0.03^{*}$ & 0.01 & 0.01 & 0.01 \\
\hline Chronic health problems during pregnancy & $0.10^{\star *}$ & 0.04 & $0.13^{\star *}$ & 0.04 \\
\hline Maternal age at stillbirth & $-0.01^{*}$ & 0.00 & 0.00 & 0.00 \\
\hline Intrapartum death & 0.04 & 0.06 & $0.14^{*}$ & 0.07 \\
\hline Abuse during pregnancy & $0.25^{\star \star \star}$ & 0.08 & $0.24^{\star \star}$ & 0.09 \\
\hline Non-white respondent & -0.05 & 0.06 & -0.07 & 0.06 \\
\hline High school educated $†$ & 0.09 & 0.05 & $0.11^{*}$ & 0.05 \\
\hline Single, divorced or widowedł & 0.06 & 0.08 & $0.24^{\star \star}$ & 0.09 \\
\hline Recruited into sample§ & -0.05 & 0.04 & -0.03 & 0.05 \\
\hline ANOVA $F$-statistic & $4.72^{\star \star *}$ & & $7.52^{\star \star \star}$ & \\
\hline$R^{2}$ & 0.08 & & 0.12 & \\
\hline
\end{tabular}

Table 3 Ordinary least-squares regression models of levels of anxiety and depression for mothers of stillborn infants $(N=769)$

${ }^{\star \star} P \leq 0.01$ (Two-Tailed). ${ }^{\star * \star} P \leq 0.001$ (Two-Tailed). †Reference is College Educated. ‡Reference is Married/Cohabitating. §Reference is Actively Sought out Recruitment.

In order to more fully explore the bivariate relationships revealed in Table 2, we report in Table 3 two multiple OLS regression models assessing the influence of social support on maternal anxiety and depression. As the results show, most of the negative bivariate relationships noted above do not appear to be significant in a multivariate model. In fact, once we account for initial differences between the women in the sample and the characteristics of their stillbirth experiences, only family support remains associated with substantially lower levels of maternal anxiety and depression in the period after stillbirth.

However, some additional findings of interest do emerge from the models reported in Table 3. For instance, the model reveals that while maternal depression wanes as time passes, levels of maternal anxiety do not. Another interesting finding - and one that appears to be closely associated with the relationship between family support and depression noted above - is that mothers who are single, divorced or widowed experience higher levels of 
depression after a stillbirth than those who are either married or cohabitating. However, when considering this evidence, it is also important to note that the $R^{2}$ values reported in Table 3 reveal that most of the variation in levels of maternal anxiety and depression following stillbirth is not explained by the variables included in the study's regression models.

Lastly, we next estimated a series of OLS regression models that incorporated various interactions between the forms of social support considered in the study. Contrary to expectations, these models revealed that the presence of support from multiple sources has no unique influence on either anxiety or depression for mothers in this sample. Thus, to conserve space, we do not report these findings in tabular format (results available from the authors upon request).

\section{Discussion}

The deleterious effects of stillbirth for mothers and their families make it a serious public health concern. Consistent with expectations and prior literature, descriptive statistics for the study's sample revealed high levels of anxiety and depression amongst stillbirth mothers using the recommended $>1.75$ as a criterion to measure mental health problems specifically for women. Veijola et al. (2003) also found that a score of 1.55 'was moderate in screening for cases of present axis-I DSM-III-R disorders' (p.57). Summary statistics demonstrate mixed evidence regarding the presence of social support for stillbirth mothers. As others have noted, women often have a desire to reach out for nurturance from others, from resources outside the self during both the acute and chronic crisis after stillbirth. While a majority of mothers in our sample received support from at least one of each of the four external sources considered in the study, only $35 \%$ of those studied experienced stillbirth with the full range of support available to them (i.e. support from doctors, nurses, family and support groups). The least commonly reported sources of support were the women's physicians and support groups. Considering that involvement in community-based support groups is voluntary, while interaction with an obstetrician during stillbirth is most often not voluntary, the fact that one-third of the sample perceived no support from their physicians at the time of the stillbirth is particularly disconcerting. However, previous studies have found that bereaved parents have 'mixed experiences with their care providers with a high number expressing discomfort or dissatisfaction with specific interactions' or insensitivity (Gold 2007, p. 232). In addition, some physicians, particularly obstetricians, 'are uncomfortable with death and avoid frank discussions with patients' experiencing stillbirth, and 'this is especially true in cases wherein the clinician is worried about being at fault' (Bright 1991, Silver 2007, p. 164).

With the above-noted evidence in hand, a series of preliminary bivariate analyses revealed that stillbirth mothers who perceived social support from doctors, nurses and family members had lower levels of both anxiety and depression than those who did not receive such support. While significantly and negatively associated with maternal depression, the presence of group support in the period after stillbirth is unrelated to levels of maternal anxiety.

After accounting for individual-level characteristics that may influence anxiety and depression, family support is the only form of social support considered in the study that reduces levels of maternal anxiety and depression. Consistent with the relationship between family support and depression, our analyses also revealed that women who are single, divorced or widowed experience higher levels of depression after a stillbirth. Interestingly, and contrary to expectations, the estimation of subsequent models incorporating various two-, threeand four-way interactions terms revealed that multiple layers of social support have no unique influence on anxiety and depression beyond their mere additive effects.

\section{Limitations}

Although our study provides important evidence regarding relationships between social support and levels of anxiety and depression amongst stillbirth mothers, some limitations should be kept in mind when evaluating our findings. This study has the advantage of a very large number of participants, needed to enable the inclusion of significant confounders in the analyses. However, despite a broad-based approach for recruitment, bias may be introduced not only by depending on informed consent from participants, but also by a skewed recruitment of participants in comparison to a total population. Participants represent younger and higher socio-economic groups (Internet access), and the adjustments for age and educational level in our analyses will not fully correct this fact. Respondents of the Internetbased survey that provided our data were more likely to be white, college educated, married, an urban resident, and a member of the middle or upper class. The participants of this study were not representative of the general population of stillbirth mothers. The under-representation of lower-class respondents is particularly salient given some evidence that family structure varies by socioeconomic status. If, for example, low socio-economic status families are less capable of providing meaningful social support, we might expect to find that family support does not have the same effects for low socioeconomic status mothers as it does for their more affluent 
counterparts. Similarly, future studies based on a more representative sample could easily reveal that lowincome mothers might be better served by more diverse social support systems and resources (e.g. multiple layers of support).

Many women were recruited while actively searching for support or information about stillbirths on the Internet and thus had more symptoms. Participants' self-selection into the study may be correlated with characterologic traits that may influence the woman's psychological response to having a stillborn baby. Methodologically, the selection effect from self-selected participants may compromise the generalisability of the outcomes. In addition, a portion of the study focuses on the perceptual experiences of women while interacting with caregivers. There is the potential for recall bias in the rating of the experiences with caregivers, particularly for the women who may have acute dysthymic disorders which pre-dated the stillbirth. There is also the potential that caregivers identified the less anxious mothers and thus they may have been more likely to include them in decision-making around holding and seeing the baby who died. The use of parental support groups for recruitment may introduce bias by recruiting stillbirth parents with fixed views. It is also possible that by the mere nature of retrospective observational studies, women who had higher levels of anxiety and depression may simply perceive lower degrees of social support given their mental condition.

A second limitation pertains to our inability to account for variability in the exact nature of social support provided by each of the four sources considered in the study. While social support's definition has been a subject of great controversy, some theorists have attempted to identify types of support. For example, social support can take four chief channels as outlined by Glanz et al. (2002): affiliation or emotional support (a sense of belonging), instrumental support (a safe place for dialogue), informational support (practical aid) and appraisal (normalisation and social comparison). Unfortunately, our data did not permit us to examine these channels of support individually. Rather, we examined an individual mother's perception of the social support offered to her during and after stillbirth.

A final caveat pertaining to our study's findings once again pertains to data limitations. More precisely, we were unable to incorporate into our models a variety of potentially relevant control variables. For example, while drug and alcohol use, marital satisfaction, and one's mental health history undoubtedly influence levels of anxiety and depression, we were unable to account for variations in these attributes across our sample of stillbirth mothers. While the influence that this potential model misspecification may have had on our findings is unclear, we were able to account for other individual-level characteristics that may be closely associated with these potentially important and unmodelled variables. For example, we include measures of physical and psychological abuse, as well as chronic health problems, which may serve (in some capacity) as proxies for indicators of marital satisfaction and or drug/alcohol use. Because of its limitations, this study could serve as springboard for future research, perhaps a mixed methods study that could ascertain, more specifically, the understanding and experiences of social support from the bereaved mother's perspective. Future studies, for example, could be phenomenological in nature, exploring who supported her and why that support was meaningful, data that could not be captured with a purely quantitative method. Perhaps, it would be beneficial to test specific interventions that are universally accepted as supportive and work towards an accepted definition for bereavement support. Additionally, a series of personality trait measures might be helpful in determining the relationship between support and perception of support.

\section{Implications}

While previous studies on conjugal bereavement (Lieberman \& Videka-Sherman 1986, Caserta \& Lund 2003) and parental bereavement (Videka-Sherman 1982, VidekaSherman \& Lieberman 1985) suggest that other bereaved parents (e.g. support groups) are the predominant source of aid for those facing death, our findings suggest that family support is more important to grieving mothers. Consistent with the family stress and coping theory, family members are most likely to recognise and effectively respond to a mother's emotional and psychological needs after stillbirth. Our results suggest that the family unit is not only the most common source of support for stillbirth mothers, but support from family members has the greatest effect in reducing maternal depression and anxiety. In fact, we find that family support is the only form of social support (of those considered in this study) that is associated with reduced maternal anxiety and depression after a stillbirth. Therefore, interventions should focus on the entire family system, not solely the grieving mother. Fathers, surviving children, grandparents and other relatives should be included, when appropriate, in discussions about the loss and when providing psychoeducation prior to hospital discharge.

\section{Conclusion}

A woman's perception of a compassionate and caring support system may help to reduce feelings of isolation and lend hope (Kish \& Holder 1996, Anke \& Fugl-Meyer 
2003). Many women experience some degree of social support after a baby's death; however, the most often reported source is from family members. Of all the sources of support, good family support appears to provide this acknowledgement resulting in greater psychological benefit, as mothers in this study with high family support were less anxious and depressed. Contrary to what we expected, the other sources of support did not have significant effects on maternal anxiety and depression. Intuitively, family members also have more opportunities to provide such intimate support on a day-to-day basis.

Despite the fact that social support networks are particularly important to women (DeFrain 1986, Hurdle 2001), very few women in this study reported having received multiple layers of support from caregivers and support groups. These findings suggest that professionals and community members could be more diligent in responding to the emotional needs of women and their families experiencing stillbirth. These outcomes can be used to make practice recommendations for hospital perinatal bereavement programmes and community healthcare agencies that work with families after stillbirth.

One such recommendation might be to implement an ecological-based support programme in order to promote family resiliency (Boss 2001). A family-centred protocol that supports, educates and provides debriefing for partners or spouses, surviving children and other family members on how to help the grieving mother in the months subsequent to the baby's death. Another policy change might be to implement a postvention protocol that includes the grieving mother and her family, rather than focusing solely on the mother. This would provide an opportunity for family members to ask questions and access resources from the bereavement team or counsellors. Single or divorced women may need additional support in order to mitigate the increased risk for anxiety and depression. The key to help the family heal after the stillbirth of a baby include the mother's acknowledgement of both the life and the death of the baby as well as a consistent, caring and sympathetic social support network (Ney et al. 1994). Community professionals should be aware of the potential risk and work towards providing a safety net for these women that is unintrusive, family inclusive and culturally appropriate.

\section{References}

Affonso D. \& Arizmendi T. (1986) Disturbances in postpartum adaptation and depressive symptomatology. Journal of Psychosomatic Obstetrics and Gynecology 5, 15.

Ananth C.V., Shiliang Liu Kinzler W.L. \& Kramer M.S. (2005) Stillbirths in the United States, 1981-2000: an age, period, and cohort analysis. American Journal of Public Health 95 (12), 2213-2217.
Anke A. \& Fugl-Meyer A. (2003) Life satisfaction several years after severe multiple trauma: a retrospective investigation. Clinical Rehabilitation 17, 431-442

Antonucci T. \& Israel B. (1986) Veridicality of social support: a comparison of principal and network member responses. Journal of Consulting and Clinical Psychology 54, 432-438.

Ballard C.G., Stanley A.K. \& Brockington I.F. (1995) Post-traumatic stress disorder (PTSD) after childbirth. British Journal of Psychiatry 166, 525-528.

Beech A. \& Robinson J. (1985) Nightmares following childbirth. British Journal of Psychiatry 147, 586.

Boss P. (2001) Family Stress Management: A Contextual Approach. Sage Publications, Thousand Oaks, CA.

Bright D.A. (1991) Stillbirth. Journal of Family Practice 32 (3), 245-253.

Cacciatore J. (2007) Effects of support groups on post traumatic stress responses in women experiencing stillbirth. Omega 55 (1), 71-91.

Caserta M. \& Lund D. (2003) Interpersonal resources and the effectiveness of self help groups for bereaved older adults. Gerontologist 33 (5), 619-629.

Cohen S., Underwood L.G. \& Gottlieb B.H. (2000) Social Support Measurement and Intervention: A Guide for Health and Social Scientists. Oxford University Press, New York.

Conde-Agudelo A., Belizan J. \& Diaz-Rossello J. (2000) Epidemiology of fetal death in Latin America. Acta Obstetricia et Gynecologica Scandinavica 79 (5), 371-378.

Copper R.L., Goldenberg R.L., DuBard M.B. \& Davis R.O. (1994) Risk factors for fetal death in White, Black, and Hispanic women: collaborative group on preterm birth prevention. Obstetrics and Gynecology 84, 490-495.

DeFrain J. (1986) Stillborn: The Invisible Death. Rowman \& Littlefield, Lexington, MA.

DeFrain J., Martens L., Stork J. \& Stork W. (1990) The psychological effects of a stillbirth on surviving family members. Omega 22 (2).

Dunkel-Schetter C. \& Bennett T. (1990) Differentiating the cognitive and behavioral aspects of social support. In: B. Sarason, I. Sarason \& G.R. Pierce (Eds) Social Support: An Interactional View, pp. 267-297. John Wiley \& Sons, New York.

Dyregrov A. \& Matthiesen S.B. (1987) Anxiety and vulnerability in parents following the death of an infant. Scandinavian Journal of Psychology 28, 16-25.

Fletcher P. (2002) Experiences in family bereavement. Family and Community Health 25 (1), 57-71.

Froen J.F. (2002) Sudden Intrauterine Unexplained Death. University of Oslo, Oslo, Norway.

Glanz K., Rimer B. \& Lewis F. (2002) Health Behavior and Health Education Theory, Research and Practice. John Wiley \& Sons, San Francisco, CA.

Gold K. (2007) Navigating care after a baby dies: a systematic review of parent experiences with health providers. Journal of Perinatology 27, 230-237.

Goldenberg R.L., Kirby R. \& Culhave J.F. (2004) Stillbirth: a review. Journal of Maternal-Fetal and Neonatal Medicine 16, 79-95.

Gundel H., O'Connor M., Littrell L., Fort C. \& Lane R.D. (2003) Functional neuroanatomy of grief. American Journal of Psychiatry 160 (11), 1946-1953.

Hankins D.V. \& Spong C.Y. (2001) Stillbirth: the overlooked obstetric tragedy. Contemporary OB/GYN 46 (12), 13-28.

Hendrick V., Altshuler L.L. \& Suri R. (1998) Hormonal changes in the postpartum and implications for postpartum depression. Psychosomatics 39 (2), 93-101. 
Hesbacher P.T., Rickels K., Morris R.J., Newman H. \& Rosenfeld H. (1980) Psychiatric illness in family practice. Journal of Clinical Psychiatry 41 (1), 6-10.

Hupcey J. (1998) Clarifying the social support theory-research linkage. Journal of Advanced Nursing 27, 1231-1241.

Hurdle D. (2001) Social support: a critical factor in women's health and health promotion. Health and Social Work 26 (2), 72-79.

Jiong Li Precht D.H., Mortensen P.B. \& Olsen J. (2003) Mortality in parents after death of a child in Denmark: a nationwide follow-up study. Lancet 361 (9355), 363.

Jung J. (1998) Social support providers - why do they help? Basic and Applied Social Psychology 9, 231-240.

Kaaya S.F., Fawzi M.C.S., Mbwambo J.K., Lee B., Msamanga G.I. \& Fawzi W. (2002) Validity of the Hopkins Symptom Checklist-25 amongst HIV-positive pregnant women in Tanzania. Acta Psychiatrica Scandinavica 106 (1), 9-19.

Kavanaugh K. (1997) Parents experience surrounding the death of a newborn whose birth is at the margin of viability. Journal of Obstetric, Gynecologic, and Neonatal Nursing 26 (1), 43-51.

Kirkley-Best E. \& Kellner K.R. (1982) The forgotten grief: a review of the psychology of stillbirth. American Journal of Orthopsychiatry 52 (3), 420-429.

Kish C. \& Holder L. (1996) Helping say goodbye: merging clinical scholarship with community service. Holistic Nursing Practice 10 (3), 74-82.

Laakso H. \& Paunonen-Ilmonen M. (2002) Mothers' experience of social support following the death of a child. Journal of Clinical Nursing 11 (2), 176-185.

LaRoche C., Lalinec-Michaud M., Engelsmann F., et al. (1984) Grief reactions to perinatal death - a follow up study. Canadian Journal of Psychiatry 29, 14-19.

Lasker J. \& Toedter L.J. (1994) Satisfaction with hospital care and interventions after pregnancy loss. Death Studies 18, 41-64.

Lehman D., Ellard J. \& Wortman C. (1986) Social support for the bereaved: recipients' and providers' perspectives on what is helpful. Journal of Consulting and Clinical Psychology 54 (4), 438-446.

Lieberman M. (1986) Social support - the consequences of psychologizing. Journal of Consulting and Clinical Psychology 54, 461-465.

Lieberman M. \& Videka-Sherman L. (1986) The impact of selfhelp groups on the mental health of widows and widowers. American Journal of Orthopsychiatry 56 (3), 435-439.

Malacrida C.A. (1999) Complicated mourning: the social economy of perinatal death. Qualitative Health Research 9 (4), 504-519.

Masten A. \& Coatsworth J. (1998) The development of competence in favorable and unfavorable environments. American Psychologist 53 (2), 205-219.

Mekosh-Rosenbaum V. \& Lasker J. (1995) Effects of pregnancy outcomes on marital satisfaction: a longitudinal study of birth and loss. Infant Mental Health Journal 16 (2), 127-143.

Michon B., Balkou S., Hivon R. \& Cyr C. (2003) Death of a child: parental perception of grief intensity - end-of-life and bereavement care. Paediatrics and Child Health 8 (6), 363-366.

Mulkay M. (1993) Social death in Britain. In: D. Clarke (Ed.) The Sociology of Death, pp. 31-49. Blackwell, Oxford.

Ney P.G., Fung T., Wickett A.R. \& Beaman-Dodd C. (1994) The effects of pregnancy loss on women's health. Social Science and Medicine 38 (9), 1193-1200.

O'Connor M. (2005) Bereavement and the brain: invitation to a conversation between bereavement researchers and neuroscientists. Death Studies 29 (10), 905-922.

O'Hara M. (1995) Postpartum Depression Causes and Consequences. Springer-Verlag, New York.
Olsen L.R., Mortensen E.L. \& Bech P. (2006) Mental distress in the Danish general population. Acta Psychiatrica Scandinavica 113 (6), 477-484.

Parloff M.B., Kelman H.C. \& Frank J.D. (1954) Comfort, effectiveness, and self-awareness as criteria for improvement in psychotherapy. American Journal of Psychiatry 3, 343-351.

Patterson J. (1988) Families experiencing stress: the family adjustment and adaptation response model. Family Systems Medicine 5 (2), 203-237.

Pauw M. (1991) The social worker's role with a fetal demise and stillbirth. Health and Social Work 16 (4), 291-297.

Pennebaker J. (1990) Opening Up: The Healing Power of Confiding in Others. Guilford Press, New York.

Rando T.A. (1984) Grief, Death, and Dying: Clinical Interventions for Caregivers. Research Press, Champaign, IL.

Rando T.A. (1993) Treatment of Complicated Mourning. Research Press, Champaign, IL.

Rubin S.S., Malkinson R. \& Witztum E. (2003) Trauma and bereavement: conceptual and clinical issues revolving around relationships. Death Studies 27 (8), 667.

Sarason B., Sarason I. \& Pierce G. (1990) Traditional views of social support and their impact on assessment. In: B. Sarason, I. Sarason \& G.R. Pierce (Eds) Social Support: An Interactional View, pp. 91-125. John Wiley \& Sons, New York.

Shalev A.Y. (2000) Biological responses to disasters. Psychiatric Quarterly 71 (3), 277.

Sheldon F. (1998) ABC of palliative care: bereavement. British Medical Journal 316 (7129), 456-458.

Silver R. (2007) Fetal death. Obstetrics and Gynecology 109 (1), 153-165.

Slade P. (2006) Towards a conceptual framework for understanding post-traumatic stress symptoms following childbirth and implications for further research. Journal of Psychosomatic Obstetrics and Gynecology 27 (2), 99-105.

Soet J.E., Brack G.A. \& Dilorio C. (2003) Prevalence and predictors of women's experience of psychological trauma during childbirth. Birth 30 (1), 36-46.

SPSS (2003) Statistical Package for the Social Sciences, Version 14.0.2 [computer program]. SPSS Inc., Chicago, IL.

Stroebe W., Stroebe M., Abakoumkin G. \& Schut H. (1996) The role of loneliness and social support in adjustment to loss: a test of attachment versus stress theory. Journal of Personality and Social Psychology 70, 1241-1249.

Stroebe W., Stroebe M. \& Abakoumkin G. (1999) Does differential social support cause differences in bereavement outcome? Journal of Community and Applied Social Psychology 9, 1-12.

Vanderwerker L.C. \& Prigerson H.G. (2003) Social support and technological connectedness as protective factors in bereavement. Journal of Loss and Trauma 9, 45-57.

Vaux A. (1988) Social Support: Theory, Research, and Intevention. Praeger Publishing, New York.

Veijola J., Jokelainen J., Läksy K., Kantojärvi L., Kokkonen P., Järvelin M.-R. \& Joukamaa M. (2003) The Hopkins Symptom Checklist-25 in screening DSM-III-R axis-I disorders. Nordic Journal of Psychiatry 57 (2), 119-123.

Videka-Sherman L. (1982) Coping with the death of a child: a study over time. American Journal of Orthopsychiatry 52 (4), 688-698.

Videka-Sherman L. \& Lieberman M. (1985) The effects of self-help and psychotherapy intervention on child loss: the limits of recovery. American Journal of Orthopsychiatry $5 \mathbf{5}$ (1), 70-82.

Zeanah C.H. \& Harmon R.J. (1995) Perinatal loss and infant mental health: an introduction. Infant Mental Health Journal 16 (2), 76-93. 